\title{
Assessment of an Insecticidal Paint for Malaria Control
}

\author{
Olufunmilola Omolade Ajayi ${ }^{1,2,}{ }^{*}$, Olufunmilayo Ajoke Idowu ${ }^{2}$, Sammy Olufemi Sam-Wobo ${ }^{2}$, \\ Ighodalo Clement Eromosele ${ }^{3}$ and Kehinde Imisiagbaraolorun Eniola ${ }^{1}$ \\ ${ }^{1}$ Department of Biological Sciences, Joseph Ayo Babalola University, Ikeji-Arakeji, Nigeria \\ ${ }^{2}$ Department of Pure and Applied Zoology, Federal University of Agriculture, Abeokuta, Nigeria \\ ${ }^{3}$ Department of Chemistry, Federal University of Agriculture, Abeokuta, Nigeria \\ "Corresponding author: Department of Biological Sciences, Joseph Ayo Babalola University, P.M.B. 5006, Ikeji-Arakeji, 08028703476, Nigeria. Email: ooajayi@jabu.edu.ng
}

Received 2020 April 02; Accepted 2020 April 20.

\begin{abstract}
Background: Plasmodium is efficiently transmitted majorly by female Anopheline mosquitoes: Anopheles funestus and Anopheles gambiae sensus lato. A gap exists with respect to primary vector control strategies; indoor residual spray requires expertise while long-lasting insecticidal nets (LLINs) cover early night sleepers.

Objectives: To cover the time between dinner and bedtime, there are commercial insecticidal paints for control of the malaria vector. It is important to monitor the efficacy of such paints. Therefore, this study was geared toward assessing the efficacy of insecticidal paint and monitoring the potency of insecticide in the paint over time.

Methods: Four rooms were painted with an insecticidal paint, and another four rooms were painted with a non-insecticidal paint. Pyrethroid Spray Catch (PSC) was performed before the rooms were painted. Anopheles mosquito larvae collected from a breeding site were reared to adults in an insectary. Twenty-five-day-old non-blood fed female mosquitoes were exposed to the painted walls using a polyvinyl chloride cone. The knock-down of mosquitoes was monitored for 30 minutes. Mortality was decided by the inability of mosquitoes to move their legs or wings after 24 hours in the holding cup. A total of 11,520 mosquitoes were used for the study.

Results: Five mosquitoes were collected from PSC prior to painting, and none were caught post painting. A 100\% knock-down rate was observed for wild mosquitoes in the first two months of exposure. The efficacy of the paint decreased in the third month, with a knock-down rate of $92.5 \%$ in 10 minutes. Moreover, the knock-down rate was not significantly different $(P>0.05)$ between the Kisumu and wild strains. Although the knock-down duration increased over time, none of the exposed mosquitoes survived. Hence, the paint is considered effective in malaria control.
\end{abstract}

Keywords: Insecticidal Paint, Anopheles Mosquitoes

\section{Background}

Malaria, a life-threatening blood disease caused by the Plasmodium parasite, is transmitted by female Anopheles mosquitoes, which carry the infective sporozoite stage of the Plasmodium parasite in their salivary gland $(1,2)$. Despite intensive attempts to control malaria, it has remained a major public health problem, particularly in tropical countries. It places a major burden on the economy of households and the health sector, as well as on worldwide development $(3,4)$. About 219 million malaria cases were reported in 2017 worldwide, with an estimated death rate of 435,000 (5). Globally, about 306,000 children under five years died of malaria. Malaria also accounted for almost 3\% of disability adjusted life years (DALYs) in 2013 (6, 7).

To combat the scourge of malaria, many approaches, such as prompt treatment, proper diagnosis, and vector control, have been put in place. In the area of vector control measures, environmental manipulation and managements were practiced. To prevent the development of larvae and their emergence to the adult stage, measures such as the introduction of molecular films and oil, insect growth regulators, predatory fish, and bacteria species (Bacillus spp) into water bodies were adopted in the past (810). However, their effectiveness was limited to permanent bodies of fresh water. Studies have not affirmed a reduction in the entomological inoculation rate (EIR) and new malaria cases $(11,12)$.

Anopheles funestus and Anopheles gambiae sensus stricto are the major Plasmodium vector species, which cause malaria disease. Most of these vector species are endophagy, biting at night, and enodphilic for the subsequent hours or days. Residual insecticide sprayed in- 
doors on walls and ceilings (IRS) as well as the insecticide treated net (ITN) was used by the World Health Organization (WHO), in collaboration with the United Nations Children's Emergency Fund (UNICEF), the United Nations Development Program (UNDP), and the World Bank, as the focus of Roll Back Malaria Global Partnership to coordinate efforts in fighting malaria (13).

Despite the widespread information about the distribution of ITNs/long lasting insecticidal nets (LLINs) for malaria control, many people do not sleep under ITNs/LLINs. Some people find sleeping under LLINs uncomfortable, while others habitually stay up late either to recreate, socialize, or study. For some, the nature of their work does not allow sleeping under the net or requires them to go to bed late. Moreover, there is still poor access to LLINs due to insufficient supply per household and low utilization by those who possess the nets (14-18). In developing novel malaria control methods, insecticidal paints have been introduced and are commercially available. However, it is necessary to assess the efficacy of insecticidal paints and monitor the duration of their effectiveness when used.

\section{Objectives}

Thus, this study aimed to assess the efficacy of insecticidal paints against Anopheles mosquitoes transmitting the malaria parasite and also the duration of their effect.

\section{Methods}

\subsection{Study Area}

The study was carried out in Ikeji, Arakeji $\left(7.508^{\circ} \mathrm{N}\right.$, $4.881^{\circ} \mathrm{E}$ ), a rural agrarian community in the Oriade local government area of Osun State. A majority of settlers in this community belong to the Yoruba ethnic group. It had a population of about 18,840 people during the National Census of 2006 (19). The two major roads into the town were the only roads laid with asphalt. Other roads were untarred and without drainages. There are pot holes and gullies in the area created by erosion.

\subsection{Preparation of Study Rooms}

Four rooms ( 3 x 3.6 square meters each) were painted with an insecticidal paint produced by Inesfly ${ }^{(\mathrm{R})}$ Africa Limited. The paint is composed of 1.5\% Chlorpyriphos, $1.5 \%$ Daizinon, and $0.063 \%$ Pyripyroxyfen, which serve as an insect growth regulator. Two layers of the paint were applied to the walls of the study rooms. Moreover, another four rooms were painted with emulsion paint without insecticide (control). The walls were painted with two layers of the paint. The study was conducted longitudinally for a year.

\subsection{Pyrethroid Spray Catch}

Pyrethroid Spray Catch (PSC) was performed to determine the mosquito density in the eight experimental rooms between 6-8 am prior to paintings, as described by WHO (20).

\subsection{Collection of Anopheles mosquito larvae}

Anopheles gambiae s.l. larvae were collected randomly from breeding sites using the dip method $(20,21)$. They were then transported and sorted into third and fourth instar larvae at the insectary section of the Biological Sciences Laboratory, the Joseph Ayo Babalola University, Ikeji, Arakeji. They were maintained at $28^{\circ} \mathrm{C}$ and $\sim 80$ humidity with a $12 \mathrm{hr}$ day/night cycle (22) and fed with $12.30 \mathrm{~g}$ of a mashed low-fat biscuit and 7.59g yeast capsules (23). The emerged mosquitoes were taken from the bowls with a mechanical aspirator and introduced into plastic cages covered with fine mesh for five days.

The larvae of the Kisumu strain of Anopheles mosquitoes was obtained from the Parasitology and Entomology Laboratory of the Nigerian Institute of Medical Research, Yaba Lagos. The larvae were maintained in the laboratory of Joseph Ayo Babalola University.

\subsection{Cone Bioassay for Susceptibility Test}

The five-day-old, non-blood fed female adult Anopheles mosquitoes were used for cone bioassay.[24] Polyvinyl chloride cones (PVCs) were fixed on the walls of the experimental rooms, with one PVC cone on each wall side of each of the rooms (Figure 1). Twenty mosquitoes were released into each of the cones using a mechanical aspirator and allowed to stand there for 30 minutes. The number of knocked-down mosquitoes were recorded at time intervals of $10,15,20$, and 30 minutes (24). After $30 \mathrm{~min}$ utes, the mosquitoes were transferred into $150 \mathrm{ml}$ holding cups (10 individuals per cup) covered with a net. A cotton wool pad soaked with $10 \%$ sugar solution was placed in each cup so that any surviving mosquito could access sugar (24). The process was also performed for the Kisumu strain. The number of deaths in each cone was recorded 24 hours after the mortality rate was determined from the pool of dead mosquitoes $(24,25)$. That is,

Observed mortality $=\frac{\text { Number of deaths }}{\text { Total number of mosquitoes }} \times 100$

A total of 11,520 mosquitoes were used for the longitudinal study. The study was conducted monthly for 12 months. 


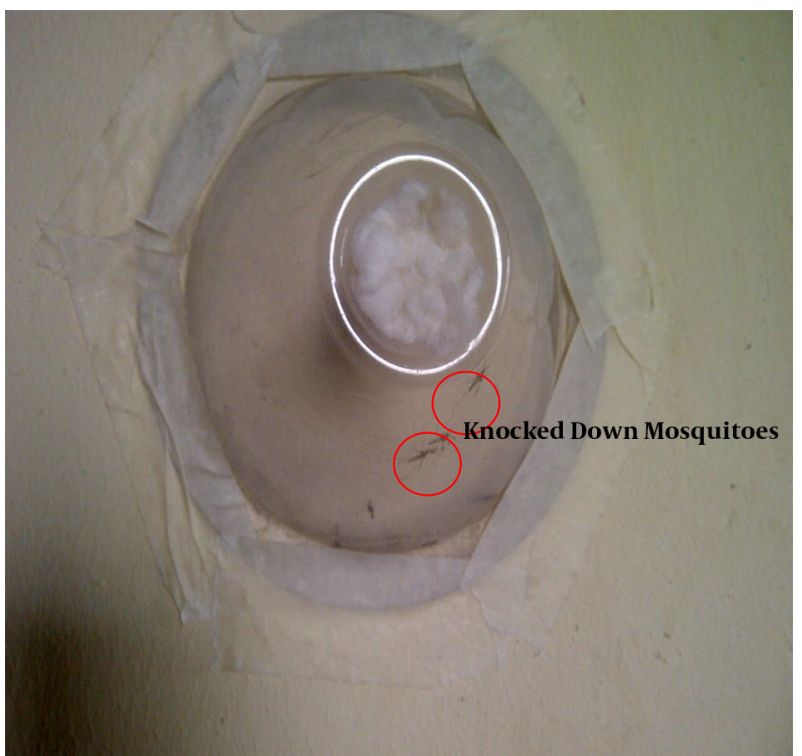

Figure 1. Polyvinyl chloride cone bioassay on the wall painted with the insecticidal paint

\subsection{Statistical Analysis}

The data were analyzed with Microsoft Excel 2013. The chi-square test was used to determine the difference in the susceptibility of the mosquito strains. Levels of statistical significance were measured at the $95 \%$ confidence interval (CI). The observations were taken to be statistically significant at $P$ value $<0.05$.

\section{Results}

Five mosquitoes were obtained from PSC before painting, while no mosquito was found in the rooms seven days post painting. A knock-down rate of $100 \%$ was observed for the wild and Kisumu strains in rooms painted with the insecticidal paint seven days post painting within 10 minutes of exposure. Moreover, a knock-down rate of $100 \%$ was observed for the mosquitos within 10 minutes of exposure in the first two months of the paint bioassay. The knock-down rate declined to $92.5 \%$ for the wild strain within 10 minutes of exposure in the third month, whereas it remained $100 \%$ for the Kisumu strain. However, there is no significant difference between the wild and Kisumu strains in terms of the knock-down rate $\left(\mathrm{X}^{2}=0.3, \mathrm{df}=1, \mathrm{P}=0.6\right)$. In the fourth-month post painting, the knock-down rate declined to $82.5 \%$ for the wild strain , although it was not significantly different $\left(X^{2}=1.6, \mathrm{df}=1, \mathrm{P}=0.2\right)$ from that for the Kisumu strain, which was 100\% (Figure 2).
The difference between the knock-down rates for the wild and Kisumu strains became significant in the sixthmonth post painting $\left(\mathrm{X}^{2}=16.7 \mathrm{df}=1, \mathrm{P}=4.5 \times 10^{-5}\right)$. In the eleventh month post painting, the knock-down rate declined to $0.0 \%$ for the exposed wild mosquitos $\left(\mathrm{X}^{2}=67.5\right.$, df $\left.=1, \mathrm{P}=2.1 \times 10^{-16}\right)$, and also, to $0.0 \%$ in the twelfth month of exposure $\left(\mathrm{X}^{2}=57.5, \mathrm{df}=1, \mathrm{P}=3.4 \times 10^{-14}\right)$ (Figure 2 ). Further, the knock-down rate for the Kisumu strain declined from $90 \%$ in the tenth month and $67.5 \%$ in the eleventh month to $57.5 \%$ in the twelfth-month post painting (Figure 2).

The total knock-down of the wild strain was observed after 15 minutes of exposure in the third to fifth month of exposure. There was also an extension of the total knockdown duration to 20 minutes in the sixth to the eighth month. However, the total knock-down duration was extended to 30 minutes of exposure in the ninth to twelfth month (Figure 3). None of the mosquitoes in the holding cups revived within 24 hours despite the provision of sugar solution in the holding cups.

\section{Discussion}

The organophosphate-based insecticidal paint was found to be effective, and total knock-down was observed for mosquitoes exposed to it. The total knock-down of mosquitoes (the wild and Kisumu strains) exposed to the insecticidal paint was observed within 10 minutes of exposure until the second month post painting. However, mosquitoes exposed to walls painted with the paint without insecticide were not knocked down. The short knockdown duration indicates the susceptibility of mosquitoes in the study environment to organophosphate insecticide. However, Awolola (26) reported the resistance of mosquitoes in Osun State to other the WHO approved classes of insecticide. The ability of a paint to release insecticide to effectively knock down mosquitos in a short time is a desirable outcome for controlling the malaria vector.

Painting walls with such paints will break the transmission of malaria parasites by the mosquito vector.

Although the insecticidal paint was effective in knocking down mosquitoes, its efficacy began to decrease after the first two months. The knock-down duration to achieve a 100\% knock-down rate was observed to extend to $15 \mathrm{~min}$ utes from the third to fifth month, 20 minutes from the sixth to eighth month, and 30 minutes from the ninth to twelfth-month post painting. This suggests that the insecticidal paint did not totally lose its potency and only required an extended exposure period. The lethal effect of the insecticidal paint in this study is in consonance with the study conducted by Mosqueira et al. (27).

Retention of potency by the insecticidal paint was further confirmed by a mortality rate of $100 \%$ for the exposed 


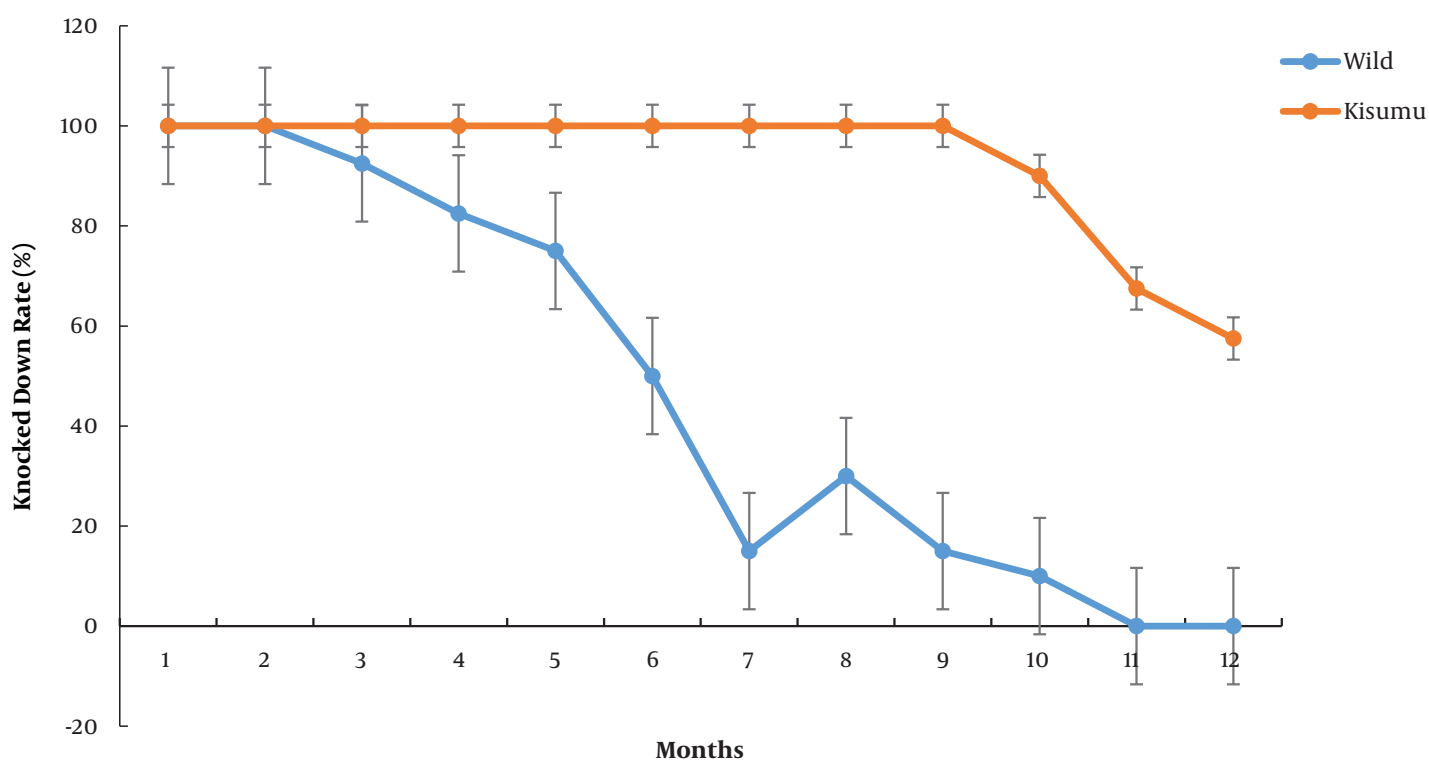

Figure 2. The knock-down rate for mosquitoes exposed to the insecticidal paint within 10 minutes

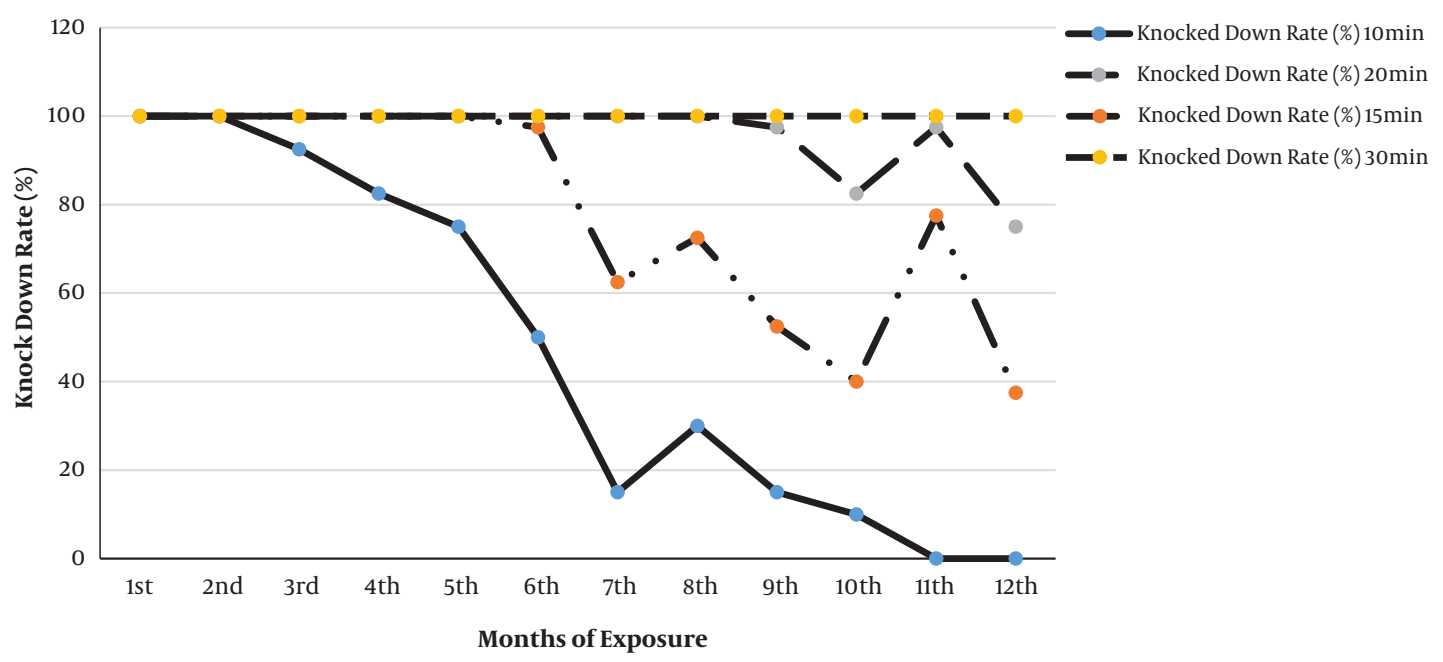

Figure 3. The trend in the knock-down rate of the insecticidal paint for the exposed wild mosquitoes during the longitudinal study

mosquitoes obtained throughout the longitudinal study. WHO (1) determines the mortality rate between $98 \%-100 \%$ as the index of the susceptibility of mosquitoes to insecticide. Therefore, the mortality rate obtained in this study was an indication of the susceptibility of mosquitoes to insecticide implanted in the paint. The high mortality rate found in this study is also in agreement with the research conducted by Mosqueira et al (28) where a high mosquito mortality rate was found after exposure to the insecticidal paint.
The zero mortality rate among mosquitoes exposed to walls painted using a non-insecticidal paint, in contrast to the $100 \%$ mortality rate among mosquitoes exposed to walls painted with the insecticidal paint, shows that the variable responsible for the knock-down of mosquitoes was insecticide in the paint, and not chemicals used for the production of the paint. Therefore, the use of insecticidal paints will be an effective intervention for malaria vector control and will provide protection for those unable to sleep under LLINs during mosquito biting hours. 


\section{Footnotes}

Authors' Contribution: Study concept and design: O. O. A and O. A. I.; data acquisition: O. O. A.; analysis and interpretation of data: O. O. A., O. A. I., and K. I. E.; drafting of the manuscript: O. O. A., O. A. I., and K. I. E.; critical revision of the manuscript for important intellectual content: I. C. E. and K. I. E.; statistical analysis: O. O. A. and K. I. E.; study supervision: O. A. I. and S. O. S.

Conflict of Interests: There is no conflict of interest.

Ethical Approval: It was obtained from Health Planning, Research and Statistic Department of the Osun State Ministry of Health, Nigeria. Ref. No. OSHREC/PRS/569T/69

Funding/Support: The study was self-supported.

\section{References}

1. World Health Organization. Monitoring and managing insecticide resistance in Aedes mosquito population Interim guidance for entomologist. Geneva, Switzerland: WHO Press; 2016.12 p.

2. Center for Disease Control and Prevention; Global Health-Division of Parasitic Diseases and Malaria. Malaria.2018, [cited 2018 Nov14]. Available from: www.cdcgov.gov.

3. Onwujekwe O, Uguru N, Etiaba E, Chikezie I, Uzochukwu B, Adjagba A. The economic burden of malaria on households and the health system in Enugu State southeast Nigeria. PLoS One. 2013;8(11). e78362. doi: 10.1371/journal.pone.0078362. [PubMed: 24223796]. [PubMed Central: PMC3817251].

4. Center for Disease Control and Prevention; Global Health-Division of Parasitic Diseases and Malaria. History of Malaria, an Ancient Disease. 2012. Available from: www.cdcgov.gov.

5. World Health Organization. World Malaria report. Global Malaria Programme. Geneva: World Health Organization; 2018.195 p.

6. Harvey V, Fineberg MD. Pandemic preparation and response of malaria. N Eng Journal of Med. 2014;307:1335-42.

7. World Health Organization. Fact sheet on the World Malaria Report. World Health Organization; 2014.

8. Fillinger U, Ndenga B, Githeko A, Lindsay SW. Integrated malaria vector control with microbial larvicides and insecticide-treated nets in western Kenya: a controlled trial. Bull World Health Organ. 2009;87(9):655-65. doi: 10.2471/blt.08.055632. [PubMed: 19784445] [PubMed Central: PMC2739910].

9. Ohba SY, Ohashi K, Pujiyati E, Higa Y, Kawada H, Mito N, et al. The effect of pyriproxyfen as a "population growth regulator" against Aedes albopictus under semi-field conditions. PLoS One. 2013;8(7). e67045. doi: 10.1371/journal.pone.0067045. [PubMed: 23843982]. [PubMed Central: PMC3699564].

10. Mbare O, Lindsay SW, Fillinger U. Pyriproxyfen for mosquito control: female sterilization or horizontal transfer to oviposition substrates by Anopheles gambiae sensu stricto and Culex quinquefasciatus. Parasit Vectors. 2014;7:280. doi: 10.1186/1756-3305-7-280. [PubMed: 24954695]. [PubMed Central: PMC4082483].

11. Mohamed AA. Study of larvivorous fish for malaria vector control in Somalia, 2002. EMHJ-Eastern Mediterranean Health Journal. 2003;9(4):618-26.

12. Walshe DP, Garner P, Adeel AA, Pyke GH, Burkot TR. Larvivorous fish for preventing malaria transmission. Cochrane Database of Systematic Reviews. 2017;2017(12). doi: 10.1002/14651858.
13. World Health Organization. Test procedures for insecticide resistance monitoring in malaria vectors, Bio-efficacy and persistence of insecticides on treated surfaces. Geneva, Switzerland: World Health Organization; 1998. $44 \mathrm{p}$.

14. Idowu OA, Sam-Wobo SO, Oluwole AS, Adediran AS. Awareness, possession and use of insecticide-treated nets for prevention of malaria in children under five in Abeokuta, Nigeria. J Paediatr Child Health. 2011;47(3):117-21. doi: 10.1111/j.1440-1754.2010.01898.x. [PubMed: 21091583]

15. Auta A. Demographic Factors Associated with Insecticide Treated Net use Among Nigerian Women and Children. $N$ Am J Med Sci. 2012;4(1):40-4. doi: 10.4103/1947-2714.92903. [PubMed: 22393547]. [PubMed Central: PMC3289489].

16. Aderibigbe SA, Olatona FA, Sogunro O, Alawode G, Babatunde OA, Onipe AI, et al. Ownership and utilisation of long lasting insecticide treated nets following free distribution campaign in South West Nigeria. Pan Afr Med J. 2014;17:263. doi:10.11604/pamj.2014.17.263.3927. [PubMed: 25309663]. [PubMed Central: PMC4189870].

17. Raghavendra K, Chourasia MK, Swain DK, Bhatt RM, Uragayala S, Dutta GDP, et al. Monitoring of long-lasting insecticidal nets (LLINs) coverage versus utilization: a community-based survey in malaria endemic villages of Central India. MalarJ. 2017;16(1):467. doi:10.1186/s12936-0172117-0. [PubMed: 29149892]. [PubMed Central: PMC5693530].

18. Israel OK, Fawole OI, Adebowale AS, Ajayi IO, Yusuf OB, Oladimeji A, et al. Caregivers' knowledge and utilization of long-lasting insecticidal nets among under-five children in Osun State, Southwest, Nigeria. Malar J. 2018;17(1):231. doi:10.1186/s12936-018-2383-5. [PubMed: 29914488]. [PubMed Central: PMC6006692].

19. Badiora AI, Abiola OB. Quality of Life (QoL) of Rural Dwellers in Nigeria: A Subjective Assessment of Residents of Ikeji-Arakeji, Osun-State. Annals of Ecology and Environmental Science. 2017;1(1):69-75.

20. World Health Organization. Training Manual on Malaria Entomology for Entomology and Vector Control Technicians (Basic Level). IVM Mal Infec Dis Task Order 2. World Health Organization; 2012.

21. O'malley C. Seven ways to a successful dipping career. Wing Beats. 1995;6:23-4.

22. Das S, Garver L, Dimopoulos G. Protocol for mosquito rearing (A. gambiae). J Vis Exp. 2007;(5):221. doi: 10.3791/221. [PubMed: 18979019]. [PubMed Central: PMC2557088].

23. Oyewole IO, Ogunnowo AA, Ibidapo CA, Okoh HI, Awolola TS, Adedayo MA. Epidemiology of malaria and insecticide resistance burden in Nigeria. Journal of public health and epidemiology. 2011;3(1):6-12.

24. World Health Organization. Test Procedures for Insecticide Resistance monitoring in Malaria Vector mosquitoes. WHO Library Cataloguing- inPublication Data.2013.39 p.

25. World Health Organization. Guidelines for Testing Mosquito Adulticides for Indoor Residual Spraying and Treatment of Mosquito Nets. Control of Neglected Tropical Diseases Who Pesticide Evaluation Scheme. World Health Organization; 2006.

26. Awolola TS. Implication of Pyrethroid Insecticides resistance on the usage of long lasting insecticidal nets in Nigeria. 2017. Available from: https: //nimr.gov.ng/nimr/wp-content/uploads/2017/06.

27. Mosqueira B, Chabi J, Chandre F, Akogbeto M, Hougard JM, Carnevale $P$, et al. Efficacy of an insecticide paint against malaria vectors and nuisance in West Africa-part 2: field evaluation. Malar J. 2010;9:341. doi: 10.1186/1475-2875-9-341. [PubMed: 21108820]. [PubMed Central: PMC3004939].

28. Mosqueira B, Soma DD, Namountougou M, Poda S, Diabate A, Ali $\mathrm{O}$, et al. Pilot study on the combination of an organophosphatebased insecticide paint and pyrethroid-treated long lasting nets against pyrethroid resistant malaria vectors in Burkina Faso. Acta Trop. 2015;148:162-9. doi: 10.1016/j.actatropica.2015.04.010. [PubMed: 25959771]. 